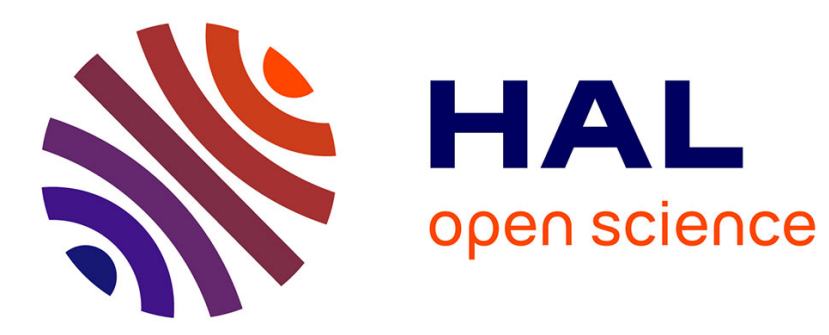

\title{
Capability-Based Implementation of Digital Service Innovation in SMEs
}

David Görzig, Susann Kärcher, Thomas Bauernhansl

\section{To cite this version:}

David Görzig, Susann Kärcher, Thomas Bauernhansl. Capability-Based Implementation of Digital Service Innovation in SMEs. IFIP International Conference on Advances in Production Management Systems (APMS), Sep 2019, Austin, TX, United States. pp.502-509, 10.1007/978-3-030-30000-5_62 . hal-02419255

\section{HAL Id: hal-02419255 \\ https://hal.inria.fr/hal-02419255}

Submitted on 19 Dec 2019

HAL is a multi-disciplinary open access archive for the deposit and dissemination of scientific research documents, whether they are published or not. The documents may come from teaching and research institutions in France or abroad, or from public or private research centers.
L'archive ouverte pluridisciplinaire HAL, est destinée au dépôt et à la diffusion de documents scientifiques de niveau recherche, publiés ou non, émanant des établissements d'enseignement et de recherche français ou étrangers, des laboratoires publics ou privés.

\section{(c)(1)}

Distributed under a Creative Commons Attribution| 4.0 International License 


\title{
Capability-based Implementation of Digital Service Innovation in SMEs
}

\author{
David Görzig 1,2[0000-0003-2047-8274], Susann Kärcher 20000-0002-1055-028X] \\ and Thomas Bauernhansl $1^{1,2[0000-0001-5768-2055]}$ \\ ${ }^{1}$ IFF University of Stuttgart, Nobelstr. 12, 70569 Stuttgart, Germany \\ ${ }^{2}$ Fraunhofer IPA, Nobelstr. 12, 70569 Stuttgart, Germany \\ dvg@iff.uni-stuttgart.de
}

\begin{abstract}
In order to be successful in the market in the long term, enterprises must not only continuously optimize their operations but also constantly innovate. It is necessary to develop radically new digital services which disrupt their existing business model. For small and medium-sized enterprises (SMEs), it is a major challenge to put the generated solutions into practice. They have to cope with digitalization while having limited resources. The presented paper starts by examining the challenges for SMEs in the context of digitalization. Thus, an analysis of the approaches used in practice for implementing digital services in 36 SMEs is carried out. Essential differences between start-ups and established SMEs are identified. On this basis, a capability-based, agile methodology is presented which supports enterprises in advancing newly developed, digital services from prototype status to the customer's environment. Finally, the methodology is put into practical application within an innovation project in an SME.
\end{abstract}

Keywords: Service Development, Innovation, Capability-based, Digitalization.

\section{Introduction}

In the context of digitalization, new service-based business models are developed that confront established market actors with major challenges [1]. Physical products are transformed into digital services that adapt to the customer's individual context. In order to remain competitive, established enterprises must succeed in digitally transform their product portfolio and transfer the resulting changes into an operational business. This includes the deep integration of people and technology as well as high customer involvement. [2] Most challenges usually arise during the transition from the first demonstrators to the operating service system at the customer's site. [3] Small and medium-sized enterprises (SMEs) have to face these challenges with a lack of financial resources and competencies. For this reason, they have to be particularly efficient in the application of their resources. [4] The objective of this paper is to present a methodology for advancing digital services of SMEs from prototype status to the live production environment. As a research methodology a design science approach is applied. First, the problem is formulated in chapter two. Then, a capability-based methodology is invented and finally applied and reflected in a first use case. This paper describes just 
the first iteration. The methodology will be continuously developed in future projects. [5]

\section{Digital Service Innovation in SMEs}

In order to be able to examine the processes of the implementation of digital service innovation in SMEs more closely, the necessary terminology must be defined first. A service is a process in which resources (e.g. goods, knowledge and skills) are applied for the benefit of others or oneself. Thus, the focus is no longer on the physical product, but on the benefit achieved. [2] Innovation is a phase of technical ontogenesis. It starts with cognition, the scientific investigation of unknown natural phenomena. If the inventions based on this are technically implemented and brought onto the market, the term "innovation" can be used. [6] The term 'digital' covers gathering, storing, processing, providing and using information electronically with the help of information technology (IT). [2] Important methodologies for the implementation of digital service innovations are for example agile approaches like Scrum. [7] In this paper, the implementation of the innovation is examined in particular. Technical aspects, as well as the requirements of employees and customers, are considered. The process of invention and the actual market launch are not taken into account.

\subsection{Analysis of Digital Service Innovation in SMEs}

The approach presented in this paper focuses on SMEs which act as digital service providers. SMEs can be characterized as enterprises with fewer than 250 employees and a turnover of less than 50 million euros [8]. They have considerably fewer resources to implement service innovations. SMEs lack investment capital, which leads to increased pressure to succeed in innovation projects. Besides, they frequently do not have the competencies required for the realization of digitalization projects. [4] For a more in-depth analysis, it is necessary to examine the current methodology of SMEs. Therefore, the following section analyzes how SMEs are currently dealing with the challenges in the implementation and introduction of digital services. It is based on an analysis of the funding measure "Industrie 4.0 Testbeds for SMEs", which offers the opportunity to advance existing inventions towards market maturity with the help of shortterm testing and development activities in research institutes. In 2018, a total of 36 SMEs who participated in the funding measure were interviewed in a semi-structured manner about their processes in service innovation. The SMEs belong to the information and communication sector (13), the manufacturing sector (10), the scientific and technical services (8) and other sectors (5). The main differences in the implementation and introduction procedures can be observed between start-ups and enterprises that have been established on the market for a long time. In the following, these differences are further detailed. The results are summarized in Table 1.

Start-ups. 14 out of the 36 analyzed enterprises can be characterized by the fact that they are operating on the market for less than five years. All of them are very focused 
on the development and operation of just a single service innovation. The implementation is very methodical. Based on an elaborated business model, agile approaches (e.g. scrum) are used in eleven of the start-ups for operational implementation of user stories. If there are existing contacts, lead customers are strongly involved in the development activities in ten of the enterprises. However, most start-ups are technology-driven. The know-how required for implementation is systematically built up. Development and operations of the product are supervised by the same people, which makes an internal product launch unnecessary.

Established SMEs. The SMEs of this group have been on the market for an average of 23 years. They have already well-established physical products and services. Only six of the analyzed enterprises are developing a completely new range of services. 16 of the 22 enterprises are trying to further develop their existing range of products to digital services. The implementation of the strategy and the development process in all enterprises are strongly driven by the managing director and are not explicitly planned. Mostly, a rough and technology-based vision was formulated, which addresses a clearly defined customer need. Based on this, a first prototype is developed. Customer feedback only takes place at the end of development. (Waterfall model) Generally, only little methodical support was applied in the investigated enterprises of this group. The execution is mostly carried out by the R\&D department. The projects are realized in groups of two or three employees. Only five projects involve employees from operations. Often, the necessary competencies for development are only available at partners like research institutes or software companies.

Table 1. Comparison of development approaches for digital service innovation.

\begin{tabular}{|c|c|c|}
\hline Criteria & Start-up & Established SME \\
\hline Product range & Focus on a single service & $\begin{array}{l}\text { Wide product range in operations } \\
\text { ties development capacities }\end{array}$ \\
\hline Strategy & Difficulties to find customer & Based on a rough vision, more \\
\hline Implementation & needs, based on a business model & focused on technology \\
\hline Methodology & Agile approach & Waterfall model \\
\hline $\begin{array}{l}\text { Operations } \\
\text { Involvement }\end{array}$ & $\begin{array}{l}\text { Same people in development and } \\
\text { operations }\end{array}$ & To limited extent \\
\hline $\begin{array}{l}\text { Customer } \\
\text { Involvement }\end{array}$ & Early involvement aimed at & $\begin{array}{l}\text { Involvement in tests after } \\
\text { development phase }\end{array}$ \\
\hline Knowledge Building & Built up systematically & Mostly covered by partners \\
\hline
\end{tabular}

\subsection{Requirements for a Methodology to Implement Digital Services}

In summary, there is a clear difference between established enterprises and start-ups. Start-ups follow agile approaches to identify customer needs and develop digital service innovation. In this way, they are continuously approaching customer needs. Established companies have deficits in their methodology. However, through their experience and deep inside to customer processes, they are able to identify highly relevant customer 
issues. What they need is an approach that supports them in formulating their digital service innovations clearly understandable and adaptable to the fast-changing customer requirements. To support such an agile approach, a central communication element is necessary, which meets the requirements of both, operations and development. Therefore, it has to be understandable without background knowledge, but also offer space for detailed considerations. Capability-based approaches can meet these requirements. Since they are not technology-oriented, but based on specific goals and benefits, capabilities link strategy, development and operations holistically. Thus, a capability-based solution approach will be pursued in the following.

\section{Capability-Based Implementation of Digital Innovations}

In this section, initially, the term capability is defined shortly. A detailed discussion can be found in [9]. Afterwards, a methodology for the development of digital service innovation in four steps is presented.

\subsection{Capability Definition}

Business capabilities are abilities or capacities that a business may possess or exchange to achieve a specific purpose or outcome [10]. Ability refers to the level of available resources like people, hardware and software needed for the performance of a process $[10,11]$. The capacity of a capability describes the scale of the outcome. [12]. In order to model capabilities based on this definition, they are regarded as a system in the following. This results in an inner and an outer view to describe capabilities.

The outer view describes the relationships among the capabilities of the value creation system. This includes the capabilities of the own enterprise, but also those of partners and customers. In this black-box description, it can be distinguished between input, output and context. The input describes the form and the type of the required variables for generating the capability. (e.g. information, materials). The output describes reliability, accuracy, scale and form of the results of a capability. (e.g. the regular provision of specific information via a defined interface) The context describes the boundary conditions under which the capability is realized. This might include a specific customer environment, a defined time frame or the available financial resources. In summary, the outer view defines the required capability performance. This definition can be made by describing specific scenarios or by a collection in a table.

Moreover, capabilities have an inner structure. This can be described on the one hand by decomposing capabilities into sub-capabilities. On the other hand, they are characterized by a process which is enabled by resources. Basically, a distinction can be made between the resources people, software and hardware. Each of them is linked to the process. Figure 1 summarizes the elements of capabilities. Further capability-based approaches can be found in the information systems literature. [9] Another approach can be found in military research. [13] A major hurdle in both approaches is their large scope. This makes it difficult to implement them in SMEs. 


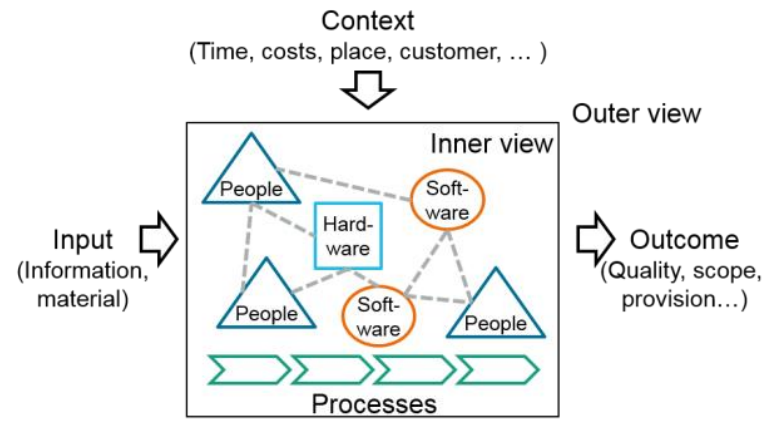

Fig. 1. Structure of capabilities

\subsection{Implementation of Capabilities}

The presented approach is based on existing agile procedures which enable a rapid response to changes in the environment such as new customer or employee requirements [14]. It consists of four steps, which are performed iteratively. First, the required capabilities are derived from the aspired service innovation and collected in a backlog. This is followed by the steps 'finding ideas', 'prototyping' and 'testing'. Fig. 2 gives an overview of the approach. The individual steps are described in detail in the following.

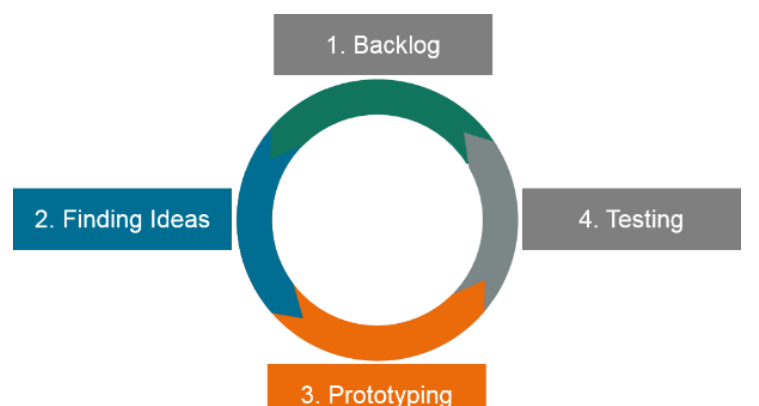

Fig. 2. Approach for capability-based service innovation

Backlog. The aim of this step is to identify the individual capabilities and their objectives. As described above, this paper starts after the invention of a new digital service. Ideally, the idea is detailed in a business model and translated into the required business capabilities. A comparison with the capabilities already available in the company follows to identify capability gaps. Missing capabilities and their requirements are documented, for example in a table. It is crucial that the outer view is first elaborated for each capability. This forms the boundary conditions under which the capability can later be used operatively. Moreover, the objectives, as well as the reliability and accuracy with which the capability must be performed, are defined. Furthermore, the timeframe of the capability deployment and the required capacity of each capability are 
defined. This includes a description of the extent to which the capability must later be implemented and what financial resources are available for it. The results for each capability are stored in the backlog.

Finding Ideas. The aim of this step is to generate and select implementation alternatives for capabilities. Therefore, the capabilities are taken from the backlog. First, it must be analyzed whether it is sufficient to adapt to existing capabilities. If this is not possible, new capabilities have to be developed. Therefore specific resource combinations are stored. Creativity techniques such as brainstorming are used. A capability can be generated in different ways. For example, a different degree of automation can be set. The generated capability alternatives are compared using a cost-utility-analysis, which enables a joint consideration of costs and benefits. A suitable capability alternative is selected. The other proposals are documented for later iterations.

Prototyping. The aim of this step is to quickly create capability prototypes by implementing the resources. These prototypes are developed in several iterations of finding ideas, prototyping and testing. In the first iterations, this can be done for example by simple storytelling or mock-ups. Requirements for people, hardware, software and interfaces can be further detailed. In later iterations, the prototypes are implemented with simple hardware, such as Arduinos or Raspberry PIs, to carry out the tests quickly at low costs. In the last step, the capability is converted into practicable hard- and software. At the same time, the competencies of the employees are gradually being developed. Therefore, education activities are systematically planned based on the required business capabilities.

Testing. The aim of this step is to test the previously generated capability prototypes with the intention to quickly generate feedback. Thus, the prototypes are immediately tested by employees and customers. Holistic feedback must be requested and all those people who are affected by the capability must be involved. Tests can be executed in different ways. One possibility is the use of test beds which is a realistic environment at a research institute. Another possibility is to test the solution together with a lead customer. The aim is to move forward step by step towards the operative application of the capability. For this purpose, the capability can be used initially for certain customers or smaller operational scenarios.

\section{$4 \quad$ Validation}

In the following, the approach presented above is applied to a service innovation project. Innovation provider is a consulting company that wants to offer an innovative consulting service, based on the exact recording of processes and times in the manual assembly of large-volume products. The objective is to create transparency and to identify optimization potentials in assembly, data-based. A comprehensive description of the technical development can be found in Kärcher et al. [15]. 
First, the target capabilities are identified, by analyzing the aspired business model. The capabilities 'data acquisition', 'data processing' and 'information provision' are defined. For each capability, requirements are deposited. For example, the data acquisition for large components must take place with an accuracy of 0.5 seconds and an accuracy of $99 \%$. The data acquisition must be possible within a period of 7 days without interruption. The aim of the capability is to generate total process times. For this purpose, the start or end of an assembly process must be detected. The capability requirements are collected in a table which is used as a backlog. Now ideas for the implementation of the capabilities are generated. The consulting company already has the capability to record times paper-based. However, since it is not possible to sufficiently develop this capability further, the development of a new capability is aimed at. There are different possibilities. The recording is possible with the help of an app which makes the data immediately available in real time. With a higher level of automation, data can be captured with the aid of sensors (e.g. RFID, camera, sensors on components). Based on the cost-benefit analysis, the company decides to implement sensors on the components. In order to get the first feedback quickly, storytelling is used for first prototypes. For this, the procedure of the capability is presented to several stakeholders from the assembly in a workshop. In the second step, the implementation of prototypes takes place with the help of simple sensors. Only in the last step, own sensors are developed. Testing is first carried out in a test environment at a research institute where a demonstrator is set up. At the same time, competence requirements for employees were recorded. It was determined that the consultants on site needed additional knowledge in configuration and bug fixing in order to implement the capability. Appropriate training material is created and tested with the first version of the system. In the second step, the solution is introduced into the customer's assembly in small projects.

Discussion. The advantage of the approach presented in this paper is that customers and employees from the operations are involved in the development process at an early stage. By using capabilities, the development is less technology-driven and strongly geared to the benefit. This led to numerous new ideas in the presented project. In addition, the components of the service innovation were developed independently of each other. As a result, these can be reused in further service innovation projects. An important hurdle was the application of the concept of capabilities, as this was often misunderstood. Thus, a training concept should be developed.

\section{$5 \quad$ Summary and Outlook}

This paper presents a capability-based approach to implementing digital services in SMEs. The challenges of SMEs were first examined in the context of a literature search and a short study. This showed that especially established SMEs have great difficulties in implementing solutions in operations. Based on this, an agile, capability-based approach was examined in more detail and applied on a practical innovation project. A major advantage of the approach was the detachment from specific technologies. It shows how SMEs can gradually implement solutions. Through the use of capabilities, 
they remain focused and receive a holistic overview of the necessary adjustments. In addition, capabilities can be used to holistically map a situation and the customer benefit generated by the service. The application has shown that while the method is very simple to use, it is limited to smaller projects. Very complex digital service innovations, as they occur in large enterprises, can only be mapped roughly without creating too much complexity. Further work is to apply this approach to a larger group of companies. In addition, elements of change management should be integrated. For example, the approach could be broadened by the strategic planning of change.

\section{Acknowledgments}

The authors gratefully acknowledge the support from The German Federal Ministry of Education and Research (BMBF) through the I4KMU project (Grant No. 01IS16020).

\section{References}

1. Bauernhansl, T., Emmrich, V., Paulus-Rohmer, D., Döbele, M., Schatz, A., Weskamp, A.: Geschäftsmodell-Innovation durch Industrie 4.0. Chancen und Risiken für den Maschinenund Anlagenbau, p. 33. Dr. Wieselhuber \& Partner GmbH, München (2015).

2. Lusch, R., Nambisan, S.: Service innovation. A service-dominant logic perspective. MIS Quarterly 39, 155-175 (2015).

3. Ward, J., Uhl, A.: Success and Failure in Transformation. Lessons from 13 Case Studies. The Business Transformation Journal, 30-37 (2012).

4. Görzig, D., Luckert, M., Aichele, A., Bauernhansl, T.: Approaches for the Development of Digital Products in Small and Medium-sized Enterprises. In: Schmitt, R., Schuh, G. (eds.) Advances in Production Research. Springer, Cham (2019).

5. Recker, J.: Scientific Research in Information Systems. Springer Berlin (2013).

6. Ropohl, G.: Allgemeine Technologie. Eine Systemtheorie der Technik. 3nd edn. Universitätsverlag Karlsruhe, Karlsruhe (2009).

7. Schwaber, K.: Agile Software Development With Scrum. Prentice Hall (2002).

8. European Union: User guide to the SME Definition. Publications Office of the European Union, Luxembourg (2015).

9. Sandkuhl, K., Stirna, J.: Capability Management in Digital Enterprises. Springer, Cham (2019).

10. Homann, U.: A business-oriented foundation for service orientation. Microsoft Developer Network (2006).

11. Aldea, A., Iacob, M.-E., Lankhorst, M., Quartel, D., Wimsatt, B.: Capability-Based Planning WP. The Link between Strategy and Enterprise Architecture. Reading, Open Group (2016).

12. Bērziša, S., Bravos, G., Gonzalez, T. C., Czubayko, U., España, S., Grabis, J., et al.: Capability Driven Development. Business \& Information Systems Eng (57), 15-25 (2015).

13. United States Department of Defense: JCIDS Manual. (2018).

14. Uebernickel, F., Brenner, W., Pukall, B., Naef, T., Schindlholzer, B.: Design Thinking Das Handbuch. Frankfurter Societaets-Medien, Frankfurt (2015).

15. Kärcher, S., Cuk, E., Denner, T., Görzig, D., Günther, L. C., Hansmersmann, A., Riexinger, G., Bauernhansl, T.: Sensor-driven Analysis of Manual Assembly Systems. Proceedings of the 51st CIRP CMS (2018). 